\title{
Chronic use of hydroxychloroquine did not protect against COVID-19 in a large cohort of patients with rheumatic diseases in Brazil
}

\author{
Gecilmara Salviato Pileggi ${ }^{1}$, Gilda Aparecida Ferreira ${ }^{2 *}$ (i), Ana Paula Monteiro Gomides Reis ${ }^{3}$, \\ Edgard Torres Reis-Neto ${ }^{4}$, Mirhelen Mendes Abreu ${ }^{5}$, Cleandro Pires Albuquerque ${ }^{3}$, Nafice Costa Araújo ${ }^{6}$, \\ Ana Beatriz Bacchiega ${ }^{1}$, Dante Valdetaro Bianchi ${ }^{7}$, Blanca Bica ${ }^{5}$, Eloisa Duarte Bonfa ${ }^{8}$, \\ Eduardo Ferreira Borba ${ }^{8}$, Danielle Christinne Soares Egypto Brito ${ }^{9}$, Ângela Luzia Branco Pinto Duarte ${ }^{10}$, \\ Rafaela Cavalheiro Espírito Santo ${ }^{11}$, Paula Reale Fernandes ${ }^{12}$, Mariana Peixoto Guimarães ${ }^{13}$, \\ Kirla Wagner Poti Gomes ${ }^{14}$, Adriana Maria Kakehasi ${ }^{2}$, Evandro Mendes Klumb ${ }^{15}$, Cristina Costa Duarte Lanna ${ }^{2}$, \\ Claudia Diniz Lopes Marques ${ }^{10}$, Odirlei André Monticielo ${ }^{11}$, Licia Maria Henrique Mota ${ }^{3}$, \\ Gabriela Araújo Munhoz ${ }^{16}$, Eduardo Santos Paiva ${ }^{17}$, Helena Lucia Alves Pereira ${ }^{18}$, José Roberto Provenza ${ }^{19}$, \\ Sandra Lucia Euzébio Ribeiro ${ }^{18}$, Laurindo Ferreira Rocha Junior ${ }^{20}$, Camila Santana Justo Cintra Sampaio ${ }^{21}$, \\ Vanderson Souza Sampaio 22,23,24, Emília Inoue Sato ${ }^{4}$, Thelma Skare ${ }^{25}$, Viviane Angelina de Souza ${ }^{12}$, \\ Valeria Valim ${ }^{26}$, Marcus Vinícius Guimarães Lacerda $22,23,24$, Ricardo Machado Xavier ${ }^{11}$ and \\ Marcelo Medeiros Pinheiro ${ }^{4}$
}

\begin{abstract}
Background: There is a lack of information on the role of chronic use of hydroxychloroquine during the SARS-CoV-2 outbreak. Our aim was to compare the occurrence of COVID-19 between rheumatic disease patients on hydroxychloroquine with individuals from the same household not taking the drug during the first 8 weeks of community viral transmission in Brazil.

Methods: This baseline cross-sectional analysis is part of a 24-week observational multi-center study involving 22 Brazilian academic outpatient centers. All information regarding COVID-19 symptoms, epidemiological, clinical, and demographic data were recorded on a specific web-based platform using telephone calls from physicians and medical students. COVID-19 was defined according to the Brazilian Ministry of Health (BMH) criteria. Mann-Whitney, Chisquare and Exact Fisher tests were used for statistical analysis and two binary Final Logistic Regression Model by Wald test were developed using a backward-stepwise method for the presence of COVID-19.
\end{abstract}

Results: From March 29th to May 17st, 2020, a total of 10,443 participants were enrolled, including 5166 (53.9\%) rheumatic disease patients, of whom $82.5 \%$ had systemic erythematosus lupus, $7.8 \%$ rheumatoid arthritis, 3.7\% Sjögren's syndrome and 0.8\% systemic sclerosis. In total, 1822 (19.1\%) participants reported flu symptoms within the 30 days prior to enrollment, of which $3.1 \%$ fulfilled the BMH criteria, but with no significant difference between

\footnotetext{
*Correspondence: gildaferreira9@gmail.com

${ }^{2}$ Hospital das Clínicas, Universidade Federal de Minas Gerais (UFMG), Belo Horizonte, MG, Brazil
}

Full list of author information is available at the end of the article

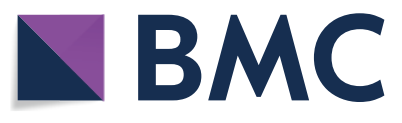

(c) The Author(s) 2021. Open Access This article is licensed under a Creative Commons Attribution 4.0 International License, which permits use, sharing, adaptation, distribution and reproduction in any medium or format, as long as you give appropriate credit to the original author(s) and the source, provide a link to the Creative Commons licence, and indicate if changes were made. The images or other third party material in this article are included in the article's Creative Commons licence, unless indicated otherwise in a credit line to the material. If material is not included in the article's Creative Commons licence and your intended use is not permitted by statutory regulation or exceeds the permitted use, you will need to obtain permission directly from the copyright holder. To view a copy of this licence, visit http://creativecommons.org/licenses/by/4.0/. 
rheumatic disease patients (4.03\%) and controls (3.25\%). After adjustments for multiple confounders, the main risk factor significantly associated with a COVID-19 diagnosis was lung disease (OR 1.63; 95\% Cl 1.03-2.58); and for rheumatic disease patients were diagnosis of systemic sclerosis (OR 2.8; 95\% Cl 1.19-6.63) and glucocorticoids above $10 \mathrm{mg} /$ day $(\mathrm{OR} 2.05 ; 95 \% \mathrm{Cl} 1.31-3.19)$. In addition, a recent influenza vaccination had a protective effect $(\mathrm{OR} 0.674 ; 95 \% \mathrm{Cl}$ $0.46-0.98)$.

Conclusion: Patients with rheumatic disease on hydroxychloroquine presented a similar occurrence of COVID-19 to household cohabitants, suggesting a lack of any protective role against SARS-CoV-2 infection.

Trial registration Brazilian Registry of Clinical Trials (ReBEC; RBR - 9KTWX6).

Keywords: COVID-19, Hydroxycloroquine, Rheumatic diseases

\section{Background}

Severe Acute Respiratory Syndrome Coronavirus (SARS-CoV-2) is the etiological agent of COVID-19, a public health emergency with relevant challenges worldwide and different epidemic curves and mortality rates between countries $[1,2]$. The disease has a heterogeneous clinical spectrum, from asymptomatic forms to severe systemic involvement, including pneumonia, cytokine storm syndrome, endotheliocyte damage, and thrombotic events [3-8].

Initial data have suggested that SARS-CoV-2 does not appear to cause more serious disease in immunosuppressed patients [9-11] and this clinical observation has drawn attention to a potential beneficial or 'protective' effect of medications used to control rheumatic diseases (RD) [12-15].

Chloroquine (CQ) and hydroxychloroquine (HCQ), immunomodulator drugs traditionally used to treat malaria and rheumatic diseases (RD), such as rheumatoid arthritis (RA), systemic lupus erythematosus (SLE), and primary Sjögren syndrome (pSS) [16-18], were pointed out as effective pharmacological strategies against COVID-19 in vitro and in anecdotal reports [19-21]. In addition, it could attenuate the cytokine storm observed in moderate or severe COVID-19 forms mitigating unfavorable outcomes. However, there are controversial data regarding their efficacy and safety to treat COVID-19 patients and a recent randomized controlled trial did not show any beneficial effect in patients hospitalized with mild-to-moderate disease when compared to standard care [22-27]. Gentry et al. did not found any significant difference regarding the incidence of active SARS-CoV-2 infection between patients with rheumatic diseases receiving hydroxychloroquine and patients without it [28].

\section{Methods}

\section{Study design and participants}

This study aimed to evaluate the frequency of COVID19 in patients with RD in HCQ, in comparison with their cohabitants during the SARS-CoV-2 pandemic in Brazil. This is a cross-sectional, observational, paired study, including adult volunteers ( $\geq 18$ years of age), with a known previous diagnosis of RD, using HCQ for at least 30 days before the initial consultation. According to the previously defined classification criteria, the cohort included patients with SLE [29]; RA [30]; pSS [31]; systemic sclerosis [32]; inflammatory myopathies [33]; mixed connective tissue disease [34]; hand osteoarthritis [35, 36], and chikungunya-related arthropathy [37].

Household cohabitants aged over 18, without RD and not using antimalarials for any purpose, were chosen as the control group to ensure more homogeneous environmental exposure to the SARS-CoV-2 infection among participants during the community viral transmission, instead of including rheumatic disease patients not using antimalarials, who would probably present a different set of diseases and different epidemiological exposure.

All participants with a history of solid organ or bone marrow transplantation, neoplasm in the previous 12 months, immunoglobulin use in the previous 30 days, current kidney replacement therapy, thymus disease, other immunodeficiencies, or positive HIV status were excluded.

Twenty-two tertiary rheumatology centers, representing the five geographic regions of Brazil and thus encompassing most of the population variability, joined the task-force study. The inclusion period was the first 8 weeks of community transmission in Brazil. This manuscript is part of a larger prospective study with 24-week follow-up.

\section{Procedures}

Participants were enrolled in this multi-center study and included through phone calls performed by previously trained medical students and physicians. Details were obtained of epidemiological and demographic data, as well as RD status and current treatment data. In addition, specific information about the COVID-19 symptoms, hospitalization, need for intensive care, and death was recorded in both groups and represents the main 
endpoints of this cohort. All the data are stored and managed using an electronic on-line platform (REDCap).

Patients taking other dosages of HCQ than $5 \mathrm{mg} /$ $\mathrm{kg} /$ day (maximum $400 \mathrm{mg} /$ day) or using CQ were not included in the final analysis.

\section{Outcomes}

The results presented in this manuscript are from a crosssectional database analysis at baseline (first telephone interview-inclusion visit) with the main outcome being the occurrence of COVID-19, according to the Brazilian Ministry of Health (BMH), within 30 days prior to enrollment [38]. Confirmatory tests have not been routinely performed in Brazil for patients with mild symptoms of SARS-CoV-2 infection, only for moderate-severe cases.

\section{Outcome definitions}

Participants in this study were defined with COVID-19, according to the most recent criteria established by the Brazilian Ministry of Health (BMH) during the pandemic period. The BMH criteria was applied to symptomatic patients based on the clinical, epidemiological and laboratory criteria, were considered as COVID-19 (Fig. 1).

\section{Statistical analyses}

Descriptive statistics were expressed as mean, standard deviation, as well as frequency (\%) and difference 95\% confidence intervals $(95 \% \mathrm{CI})$. The Kolmogorov-Smirnov test was used to verify a normal data distribution. Two binary Final Logistic Regression Model by Wald test were developed using a backward-stepwise method for the presence of COVID-19, including Odds Ratio (OR) and their respective 95\% CI. The first model considered both groups (cases and controls) and was adjusted for age, sex, lung and kidney disease, hypertension, diabetes, and influenza vaccine within the previous 30 days. The second one included only RD patients, adjusted for lung disease, corticosteroids, systemic sclerosis, and influenza vaccine within the previous 30 days. Only variables with $\mathrm{p}$ value below 0.2 found in the first model was added to the second model. A $P$-value under 0.05 was considered significant. The statistical analysis was performed using IBM-SPSS v.20.0 software.

\section{Results}

From March 29th to May 17th, 2020 (8-week period), a total of 9589 participants from 97 Brazilian cities were enrolled at baseline, including 5166 (53.9\%) patients with $\mathrm{RD}$ on $\mathrm{HCQ}(5 \mathrm{mg} / \mathrm{kg} /$ day, maximum dosage of $400 \mathrm{mg})$,

\section{SUSPECTED CASE}

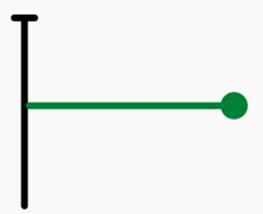

Patient with acute respiratory symptoms, including 2 of following, at least: fever, chills, sore throat, headache, cough, rhinorrhea, anosmia, dysgeusia or shortness of breathe

\section{CONFIRMED CASE}

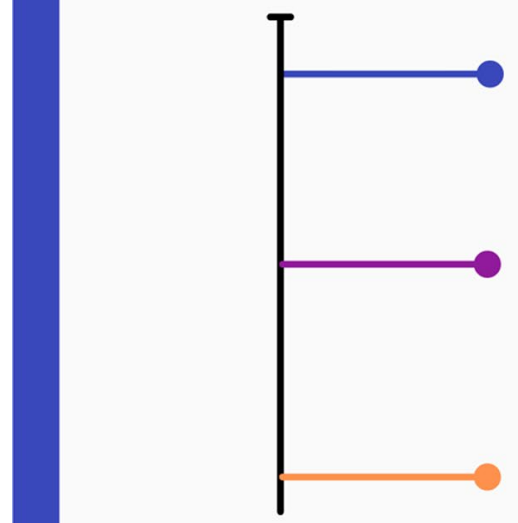

1. Clinical criterion: Suspected case PLUS anosmia OR dysgeusia (acute and no prior cause or previous episode)

2. Epidemiological criterion: Suspected case PLUS confirmed close contact or household cohabitant with COVID-19 in the last 14 days before beginning the symptoms

3. Lab criterion: Suspected case PLUS positive confirmatory test for SARS-CoV-2 by RT-PCR OR Reagent serology for IgM, IgA and/or IgG by ELISA, IC or ECLIA

Fig. 1 Outcome definition: participants were classified according to the Brazilian Ministry of Health (BMH) criteria using the definition for COVID-19. Individuals with more than 3 days of influenza-like illness symptoms were considered for this analysis 
and 4423 (46.1\%) cohabitants living in the same household. Of these, 854 (8.1\%) individuals were excluded according to the eligibility criteria (Fig. 2).

Although statistically different, the difference between the mean age and frequency of contact with a confirmed case of COVID-19 were not clinically relevant. There was a higher frequency of females in the patients' group and a higher frequency of males in the household cohabitants. All concomitant diseases evaluated were significantly more common in RD patients than the control group, except for diabetes. On the other hand, social distancing and influenza vaccination were reported more frequently by RD patients (Table 1 ).

Most of the RD patients had SLE ( $\mathrm{N}=4243 ; 82.5 \%)$, followed by RA $(\mathrm{N}=402 ; 7.8 \%)$, and pSS $(\mathrm{N}=192$; 3.7\%). Among the $5166 \mathrm{RD}$ patients, $97.5 \%$ are using $\mathrm{HCQ}$, of whom $522(10.1 \%)$ take it as monotherapy and $4644(89.9 \%)$ combined with other therapies, such as

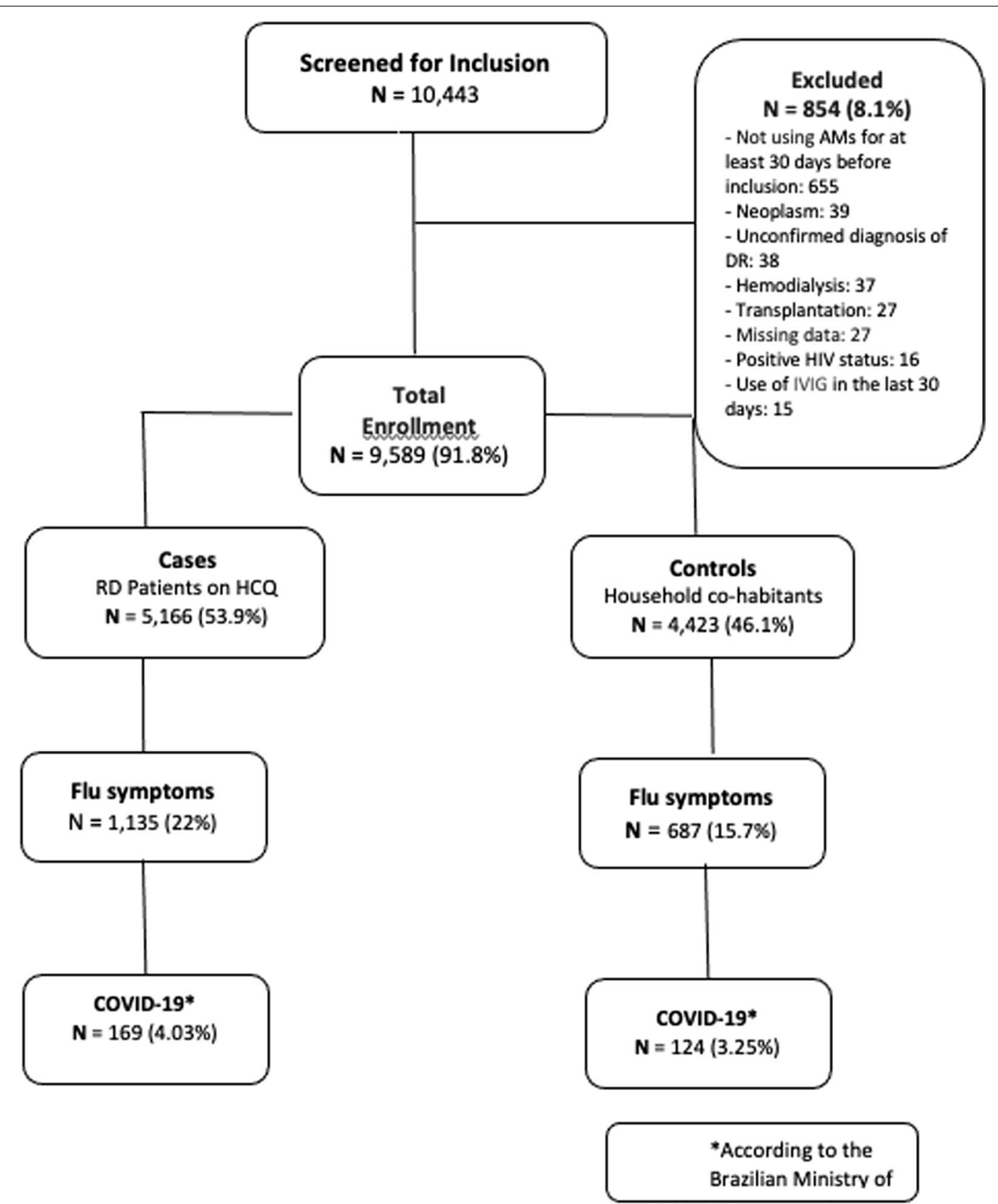

Fig. 2 Flowchart of participants enrolled in this study, considering influenza-like illness symptoms and a diagnosis of COVID-19, according to the Brazilian Ministry of Health criteria 
Table 1 Epidemiological and clinical data between patients with rheumatic diseases and household contacts at baseline

\begin{tabular}{|c|c|c|c|c|c|}
\hline \multirow[t]{3}{*}{ Variables } & \multirow{2}{*}{$\begin{array}{l}\text { All } \\
N=9589\end{array}$} & \multirow{2}{*}{$\begin{array}{l}\text { RD patients } \\
\mathrm{N}=5166\end{array}$} & \multirow{3}{*}{$\begin{array}{l}\text { Household } \\
\text { co-habitants } \\
\mathrm{N}=4423 \\
\mathrm{n}(\%)\end{array}$} & \multirow[t]{3}{*}{ Difference (Cl 95\%) } & \multirow[t]{3}{*}{$p^{*}$} \\
\hline & & & & & \\
\hline & n (\%) & n (\%) & & & \\
\hline Age, years (SD) & $43.5(14.9)$ & $43.1(13.9)$ & $44.0(16.1)$ & $0.90(0.29 ; 1.50)$ & 0.039 \\
\hline \multicolumn{6}{|l|}{ Sex } \\
\hline Women & $6617(69.4)$ & $4772(92.6)$ & $1845(42.2)$ & $50.4(48.8 ; 52.0)$ & $<0.001$ \\
\hline Men & 2912 (30.6) & $382(7.4)$ & $2530(57.8)$ & & \\
\hline \multicolumn{6}{|l|}{ Schooling } \\
\hline Basic or illiterate & $2522(26.5)$ & $1296(25.1)$ & $1226(28)$ & $2.9(1.1 ; 4.7)$ & $<0.001$ \\
\hline High school & $4027(42.2)$ & $2166(42)$ & $1861(42.6)$ & $0.6(-1.39 ; 2.6)$ & \\
\hline College & $2983(31.3)$ & $1697(32.9)$ & $1286(29.4)$ & $3.5(1.6 ; 5.4)$ & \\
\hline \multicolumn{6}{|l|}{ Profession } \\
\hline Customer assistance & $1911(20.2)$ & $946(18.5)$ & $965(22.2)$ & $3.7(2.1 ; 5.3)$ & $<0.001$ \\
\hline Healthcare & $683(7.2)$ & $443(8.7)$ & $240(5.5)$ & $3.2(2.2 ; 4.2)$ & \\
\hline Safety professionals & $182(1.9)$ & $43(0.8)$ & $139(3.2)$ & $2.4(1.8 ; 3.0)$ & \\
\hline Education & $636(6.7)$ & $438(8.6)$ & $198(4.6)$ & $4.0(3.0 ; 4.9)$ & \\
\hline Housewife & $1662(17.6)$ & $1236(24.2)$ & 426 (9.8) & $14.4(12.9 ; 15.9)$ & \\
\hline Others & $4382(46.3)$ & 2011 (39.3) & $2371(54.6)$ & $15.3(13.3 ; 17.3)$ & \\
\hline \multicolumn{6}{|l|}{ Contact with confirmed case of COVID-19 } \\
\hline No & $8136(85.3)$ & $4484(86.9)$ & $3652(83.4)$ & $3.5(2.1 ; 4.9)$ & $<0.001$ \\
\hline Yes & $727(7.6)$ & $380(7.4)$ & $347(7.9)$ & $0.5(-0.6 ; 1.6)$ & \\
\hline Unknown & $673(7.1)$ & $294(5.7)$ & $379(8.7)$ & $3.0(1.9 ; 4.1)$ & \\
\hline Family unit in social distancing & $5787(60.7)$ & $3235(62.7)$ & $2552(58.4)$ & $4.3(2.3 ; 6.3)$ & $<0.001$ \\
\hline Heart disease & $496(5.3)$ & $314(6.2)$ & $182(4.3)$ & $1.9(1.0 ; 2.8)$ & $<0.001$ \\
\hline Diabetes & $703(7.5)$ & $339(6.7)$ & $364(8.5)$ & $1.8(0.7 ; 2.9)$ & $<0.001$ \\
\hline Lung disease & $497(5.3)$ & $357(7)$ & $140(3.3)$ & $3.7(2.8 ; 4 ; 6)$ & $<0.001$ \\
\hline Kidney disease & $602(6.4)$ & $565(11.1)$ & $37(0.9)$ & $10.2(9.3 ; 11.1)$ & $<0.001$ \\
\hline Hypertension & $2673(28.6)$ & $1692(33.3)$ & $981(23)$ & $10.3(8.5 ; 12.1)$ & $<0.001$ \\
\hline Influenza vaccine within last 30 days & $2584(27.2)$ & 1527 (29.6) & $1057(24.2)$ & $5.4(3.6 ; 7.2)$ & $<0.001$ \\
\hline
\end{tabular}

Bold values indicate statistical significance $(p<0.05)$

The results are expressed as means, standard deviation and percentages

$\mathrm{Cl}$, confidence interval; RD, rheumatic diseases; COVID-19, Coronavirus disease 2019

${ }^{*}$ Chi-square test

corticosteroids (37.0\%) and immunosuppressant drugs (48.9\%). The remaining $2.5 \%$ from antimalarials users were taking other chloroquine salts, particularly diphosphate, and they were excluded from this final analysis (Table 2).

In total, 1822 (19.1\%) participants reported influenzalike illness symptoms within the 30 days prior to enrollment, of whom 293 (3.1\%) individuals fulfilled the $\mathrm{BMH}$ criteria for a COVID-19 diagnosis [38]. In general, the frequency of self-reported influenza-like illness symptoms was significantly higher in RD patients, including those with severe symptoms (such as shortness of breath), except fever and anosmia (Table 3).

Considering a COVID-19 diagnosis, there was no significant difference in the number of cases between RD patients (4.03\%) and the control group (3.25\%) (OR 0.78, $-0.05 ; 1.60)$. Men (OR 0.71; 95\% CI 0.52-0.98, $\mathrm{p}=0.043$ ) participants had lower likely of having the disease. On the other hand, individuals with previous lung disease (OR 1.63; 95\% CI 1.03-2.58, $\mathrm{p}=0.038$ ) were more likely to present clinically confirmed COVID-19 in the final logistic regression model, after adjustments for multiple confounders, using the variables with $\mathrm{p}<0.2$ in the first (Table 4).

Considering only RD patients, having systemic sclerosis and current use of glucocorticoids (daily dosage above $10 \mathrm{mg}$ ) had a harmful effect for a COVID-19 diagnosis while a recent influenza vaccination had a protective role (OR 0.674; 95\% CI 0.46-0.98), after multiple adjustments for sex, age, concomitant medication, 
Table 2 Main rheumatic diseases and concomitant medication at baseline

\begin{tabular}{lc}
\hline & N (\%) \\
\hline Rheumatic disease & \\
Systemic lupus erythematous & $4243(82.5)$ \\
Rheumatoid arthritis & $402(7.8)$ \\
Primary Sjögren syndrome & $192(3.7)$ \\
Mixed connective tissue disease & $75(1.5)$ \\
Osteoarthritis & $66(1.3)$ \\
Systemic sclerosis & $43(0.8)$ \\
Inflammatory myopathies & $34(0.7)$ \\
Chikungunya & $18(0.4)$ \\
Other & $69(1.3)$ \\
Antimalarials & \\
Hydroxychloroquine (HCQ) & $5035(97.5)$ \\
HCQ use time (years), mean (SD) & $7.2(6.2)$ \\
Chloroquine diphosphate (CD) & $131(2.5)$ \\
CD use time (years), mean (SD) & $10.6(7.4)$ \\
Concomitant medication related to RD & \\
Glucocorticoids & $1895(36.7)$ \\
$<10$ mg/day & $1394(73.6)$ \\
$\geq 10$ mg/day & $462(24.4)$ \\
Ibuprofen & $35(0.7)$ \\
IV Methylprednisolone (pulse) & $30(0.6)$ \\
Cyclophosphamide (oral and pulse) & $73(1.4)$ \\
Synthetic conventional DMARDs & $2444(47.3)$ \\
Methotrexate & $631(12.2)$ \\
Sulfasalazine & $16(0.3)$ \\
Azathioprine & $983(19.0)$ \\
Leflunomide & $96(1.9)$ \\
Cyclosporine & $80(1.5)$ \\
Mycophenolate mofetil & $657(12.7)$ \\
Biological or target-specific DMARDs & $181(3.5)$ \\
Belimimimaibitors & $52(1.0)$ \\
\hline Therimab & $81(1.6)$ \\
\hline
\end{tabular}

The results are expressed as means, standard deviation and percentages; DMARDs, disease activity-modifying drugs; some individuals are taking more than one synthetic DMARD

immunosuppressant drugs, and comorbidities, regardless of chronic HCQ use, (Table 5).

\section{Discussion}

Our results showed patients with RD on HCQ had a similar likelihood of presenting a COVID-19 diagnosis, according to the $\mathrm{BMH}$ criteria, when compared to cohabitants living in the same household during the first
8 weeks of community transmission in Brazil. Considering that according to recent studies [12, 39], patients with RD present a similar incidence of COVID-19 to the general population but with a potentially more unfavorable outcome [40,41] and higher mortality rate [42, 43], we were not able to confirm our preliminary hypothesis in demonstrating a potential beneficial effect of chronic HCQ use against SARS-CoV-2 [44] in a population that traditionally has a higher prevalence of respiratory diseases.

Moreover, our data showed a higher frequency of influenza-like illness symptoms, including those with greater severity, especially shortness of breath, in patients with RD when compared with controls, suggesting these individuals should maintain social distancing, especially those that work with customer assistance, such as healthcare, teaching, and safety professionals $[12,45-50]$. However, it is worth highlighting that patients with RD may report more symptoms than controls due to different behavior in relation to the perception of signs and symptoms because of the information they receive about their underlying disease from healthcare professionals and the combination of disease activity, as well as that the immunosuppression may predispose them to more infectious diseases that cause influenza-like illness symptoms such as influenza, adenovirus, and others [51].

Although CQ has in vitro activity against influenza, HCQ use did not prevent infection or decrease the risk of influenza infection [52-57]. Thus, our data are supported by current evidence demonstrating a lack of association between HCQ and COVID-19 considering pre-exposure (PrEP) and post-exposure prophylaxis especially in individuals at risk, such as healthcare professionals, as well as more recent randomized clinical trials, including mildmoderate and severe forms of SARS-CoV-2 infection [22, $24,26,27,58-62]$.

In our total sample, men had a lower risk of COVID19 than women (OR 0.71; 95\% CI 0.52-0.98). This aspect could be related to higher frequency of female in patients group than in the control group because of inclusion approach that prioritized household contact paired for age (husband and wife more frequently). Also, men participants had less comorbidities and used less glucocorticosteroids. The current literature has shown a similar incidence between men and women, but with a poorer outcome in the former [1, 63-65].

Patients with RD using a daily GC dosage above $10 \mathrm{mg} /$ day (prednisone equivalent), particularly above $20 \mathrm{mg} /$ day, presented a two times higher risk of COVID-19 in our cohort. These data confirm previous findings showing a harmful effect of GC on the infection rate in immunemediated RD patients, especially lupus [66], hampering the immune response against several infectious agents, 
Table 3 Self-reported influenza-like illness symptoms and a COVID-19 diagnosis in patients with rheumatic diseases and household contacts at baseline

\begin{tabular}{|c|c|c|c|c|c|}
\hline Symptoms & $\begin{array}{l}\text { All } \\
N=9589 \\
n(\%)\end{array}$ & $\begin{array}{l}\text { RD Patients } \\
N=5164 \\
\mathrm{n}(\%)^{* *}\end{array}$ & $\begin{array}{l}\text { Household } \\
\text { co-habitants } \\
N=4378 \\
n(\%) *\end{array}$ & $\begin{array}{l}\text { Difference } \\
(95 \% \mathrm{Cl})\end{array}$ & $\mathrm{p}^{*}$ \\
\hline Any & $1822(19.1)$ & $1135(22)$ & $687(15.7)$ & $6.3(4.7 ; 7.9)$ & $<0.001$ \\
\hline Fatigue & $531(5.6)$ & $328(6.4)$ & $203(4.6)$ & $1.8(0.9 ; 2.7)$ & $<0.001$ \\
\hline Headache & $734(7.7)$ & $453(8.8)$ & $281(6.4)$ & $2.4(1.3 ; 3.5)$ & $<0.001$ \\
\hline Rhinorrhea & $976(10.2)$ & $601(11.6)$ & $375(8.6)$ & $3.0(1.8 ; 4.2)$ & $<0.001$ \\
\hline Dysgeusia & $242(2.5)$ & $146(2.8)$ & $96(2.2)$ & $0.6(0 ; 1.2)$ & 0.049 \\
\hline Shortness of breath & $266(2.8)$ & $188(3.6)$ & $78(1.8)$ & $1.8(1.2 ; 2.4)$ & $<0.001$ \\
\hline Sore throat & $704(7.4)$ & $455(8.8)$ & $249(5.7)$ & $3.1(2.1 ; 4.1)$ & $<0.001$ \\
\hline Fever & $486(5.1)$ & $276(5.3)$ & $210(4.8)$ & $0.5(-0.4 ; 1.4)$ & 0.225 \\
\hline Anosmia & $209(2.2)$ & $120(2.3)$ & $89(2)$ & $0.3(-0.3 ; 0.9)$ & 0.333 \\
\hline Cough & $910(9.5)$ & $579(11.2)$ & $331(7.6)$ & $3.6(2.4 ; 4.8)$ & $<0.001$ \\
\hline Fever AND Shortness of breath & $123(1.3)$ & $80(1.9)$ & $43(1.2)$ & $0.7(0.2 ; 1,2)$ & 0.005 \\
\hline Fever AND Cough AND Shortness of breath & $83(0.9)$ & $53(1.3)$ & $30(0.8)$ & $0.5(0.1 ; 0.9)$ & 0.034 \\
\hline BMH COVID-19 criteria & $293(3.1)$ & $169(4.03 \%)$ & $124(3.25 \%)$ & $0.78(-0.05 ; 1.60)$ & 0.065 \\
\hline
\end{tabular}

Bold values indicate statistical significance $(p<0.05)$

The results are expressed as means, standard deviation and percentages

BMH, Brazilian Ministry of Health

* There are 45 missing data; **There are 2 missing

Table 4 Final logistic regression model considering all individuals enrolled at baseline

\begin{tabular}{|c|c|c|c|c|c|}
\hline \multirow[t]{3}{*}{ Variables } & \multicolumn{3}{|l|}{ Binary analysis } & \multicolumn{2}{|c|}{ Multivariate analysis } \\
\hline & \multirow{2}{*}{$\begin{array}{l}\text { No symptoms } \\
\mathrm{N}=7720 \\
\mathrm{n}(\%)\end{array}$} & \multirow{2}{*}{$\begin{array}{l}\text { Clinically Confirmed COVID-19 } \\
N=293 \\
n(\%)\end{array}$} & \multirow[t]{2}{*}{$\mathbf{p}$} & \multirow[t]{2}{*}{ OR $(95 \% \mathrm{Cl})$} & \multirow[t]{2}{*}{$P^{* * *}$} \\
\hline & & & & & \\
\hline Age (y), mean (SD); med. (min-max.) & $43.9(15.2) ; 42(18-98)$ & $41.6(13.0) ; 41(18-90)$ & $0.028^{*}$ & $0.989(0.981 ; 0.997)$ & 0.008 \\
\hline \multicolumn{6}{|l|}{ Group } \\
\hline Household cohabitants & $3691(47.8)$ & $124(42.3)$ & $0.065^{* *}$ & 1 & - \\
\hline RD patients & $4029(52.2)$ & $169(57.7)$ & & $1.10(0.83 ; 1.46)$ & 0.526 \\
\hline \multicolumn{6}{|l|}{ Sex } \\
\hline Women & $5259(68.2)$ & $218(75.4)$ & $0.01 * *$ & 1 & - \\
\hline Men & $2450(31.8)$ & $71(24.6)$ & & $0.71(0.52 ; 0.98)$ & 0.043 \\
\hline \multicolumn{6}{|l|}{ Schooling } \\
\hline Basic or illiterate & $2110(27.4)$ & $64(21.8)$ & $0.091^{* *}$ & & \\
\hline High school & $3280(42.6)$ & $139(47.4)$ & & & \\
\hline College & $2317(30.1)$ & $90(30.7)$ & & & \\
\hline Family in social distancing & $4728(61.3)$ & $172(58.9)$ & $0.402^{* *}$ & & \\
\hline Heart disease & $398(5.3)$ & $17(6)$ & $0.570^{* *}$ & & \\
\hline Diabetes & $585(7.7)$ & $17(6)$ & $0.292^{* *}$ & & \\
\hline Lung disease & $367(4.8)$ & $21(7.4)$ & $0.048^{* *}$ & $1.63(1.03 ; 2.58)$ & 0.038 \\
\hline Kidney disease & $465(6.1)$ & $23(8.2)$ & $0.169^{* *}$ & & \\
\hline Hypertension & $2165(28.6)$ & $78(27.7)$ & $0.730^{* *}$ & & \\
\hline Influenza vaccine within 30 last days & $2138(27.8)$ & $63(21.6)$ & $0.022^{* *}$ & & \\
\hline
\end{tabular}

Bold values indicate statistical significance $(p<0.05)$

Outcome is clinically confirmed COVID-19 diagnosis

$\mathrm{Y}$, years; SD, standard deviation; med., median; min., minimum; max., maximum

${ }^{*}$ Mann-Whitney test; ${ }^{* *}$ Chi-square test; ${ }^{* * *}$ Wald test by final logistic regression model 
Table 5 Final logistic regression model regarding rheumatic disease patients enrolled at baseline

\begin{tabular}{|c|c|c|c|c|c|}
\hline \multirow[t]{2}{*}{ Variables } & \multicolumn{3}{|l|}{ Binary analyses } & \multicolumn{2}{|c|}{ Multivariate analyses } \\
\hline & $\begin{array}{l}\text { No symptoms } \\
\mathrm{N}=4029 \\
\mathrm{n}(\%)\end{array}$ & $\begin{array}{l}\text { Clinical } \\
\text { Covid-19 } \\
\mathrm{N}=169 \\
\mathrm{n}(\%)\end{array}$ & $\mathbf{p}$ & OR $(95 \% \mathrm{Cl})$ & $\mathrm{P}^{* * * *}$ \\
\hline Influenza vaccine within last 30 days & $1235(30.7)$ & $39(23.1)$ & $0.034^{* *}$ & $0.676(0.465 ; 0.984)$ & 0.041 \\
\hline IV Methylprednisolone (pulse) & $21(0.5)$ & $2(1.2)$ & $0.236^{* * *}$ & & \\
\hline \multicolumn{6}{|l|}{ Glucocorticoids } \\
\hline No & $2555(63.9)$ & $97(58.1)$ & $0.004^{* *}$ & 1 & - \\
\hline$<10$ mg/day & $1099(27.5)$ & $43(25.7)$ & & $0.965(0.662 ; 1.41)$ & 0.854 \\
\hline$>=10 \mathrm{mg} /$ day & $343(8.6)$ & $27(16.2)$ & & $2.07(1.33 ; 3.22)$ & 0.001 \\
\hline scDMARDs & $1875(46.5)$ & $84(49.7)$ & $0.419^{* *}$ & & \\
\hline Biological or tsDMARDs & $120(3)$ & $7(4.1)$ & $0.387^{* *}$ & & \\
\hline RA & $317(7.9)$ & $16(9.5)$ & $0.466^{* *}$ & & \\
\hline MCTD & $56(1.4)$ & $2(1.2)$ & $>0.99^{* * *}$ & & \\
\hline SS & $39(0.9)$ & $4(2.4)$ & $0.042^{* * *}$ & $3.81(1.31 ; 11.05)$ & 0.014 \\
\hline SLE & $3304(82)$ & $134(79.3)$ & $0.414^{* *}$ & & \\
\hline IM & $26(0.6)$ & $1(0.6)$ & $0.703^{* * *}$ & & \\
\hline $\mathrm{OA}$ & $60(1.5)$ & $1(0.6)$ & $0.518^{* * *}$ & & \\
\hline pSjS & $150(3.79)$ & $6(3.6)$ & $0.560^{* * *}$ & & \\
\hline Another RD & $55(1.4)$ & $4(2.4)$ & $0.299 * * *$ & & \\
\hline
\end{tabular}

Bold values indicate statistical significance $(p<0.05)$

RA, Rheumatoid arthritis; SLE, Systemic lupus erythematous; RD, Rheumatic diseases; MCTD, Mixed connective tissue disease; SS, Systemic sclerosis; IM, Inflammatory myopathies; OA, Osteoarthritis; pSjS, Primary Sjögren syndrome; sc, synthetic conventional; ts, target-specific; DMARDs, Disease Activity-Modifying Drugs; Model 3, Outcome is COVID-19 diagnosis, according to the Brazilian Ministry of Health criteria; y, years; SD, standard deviation; med., median; min., minimum; max., maximum

* Mann-Whitney test; ${ }^{* *}$ Chi-square test; ${ }^{* * *}$ Fischer's exact test; ${ }^{* * * * W a l d ~ t e s t ~ b y ~ f i n a l ~ l o g i s t i c ~ r e g r e s s i o n ~ m o d e l ~}$

including SARS-CoV-2 [67-70]. More recently, Gianfrancesco et al. also reported a higher risk of hospitalization in individuals using more than $10 \mathrm{mg} /$ day (OR 2.05; 95\% CI 1.06-3.96) and no significant association with $\mathrm{HCQ}$, in agreement with our findings [41]. On the other hand, performing a sensitivity analysis excluding patients that received more than $10 \mathrm{mg} /$ day of glucocorticoids from the RD group, and we observed quite similar findings (data not shown), suggesting that the risk for COVID-19 did not change when adjusted for corticosteroids (high vs. low dosage). It is important taking into consideration the low daily GC dosage $(<10 \mathrm{mg}$ in almost $75 \%$ of them) and low proportion of current pulse therapy (around 2\% of cyclophosphamide or methylprednisolone).

In the final multivariate model, systemic sclerosis was the only RD related to COVID-19, regardless of interstitial lung disease or the use of $\mathrm{HCQ}$, as pointed out by some authors [71-73]. Nonetheless, an Italian phone interview study did not find any association regarding a higher risk in SS patients [39].

Interestingly, some of the main comorbidities associated with an unfavorable outcome and increased risk of death, such as diabetes, and heart and kidney diseases $[1,39,64]$ were not significantly associated with COVID-19 in our patients with RD. In addition, the self-reporting of fever and/or anosmia, more specific symptoms of COVID-19, was also not different between RD patients and controls [74].

Although post influenza vaccine side effects could also have been a potential confounding factor, we found the influenza vaccine had an independent protective role in RD patients (OR 0.674; 95\% CI 0.463-0.979), reducing the diagnosis of COVID-19 during the beginning of national vaccination campaign. Our data reinforce the effectiveness and safety of this approach in RD patients [75]. In addition, it is noteworthy pointing out this potential protective effect could be related to some bias, especially some behavioral attitudes (social distancing, strict masking and other self-care measurements) that are more observed in immunosuppressed patients.

To the best of our knowledge, this is the largest epidemiological study designed to evaluate the preventive role of HCQ to development of COVID-19 in patients with RD using HCQ. Some strengths should be considered, such as sampling size, the control group with the same epidemiological setting, weekly data quality monitoring, specific platform to collect all the information using serial, with national representation in pandemic times. 
On the other hand, it is worth emphasizing some limitations of the study that are inherent to the COVID-19 pandemic, including the need for social distancing and specific guidance for the patients to avoid seeking medical care unless absolutely necessary. Therefore, in such a large population, we have only self-reported data, and a small number of confirmatory lab tests (RT-PCR and serology) and information on disease activity. The $\mathrm{BMH}$ criteria for COVID-19 have several similarities with the US criteria to define COVID-19 [76].

Another limitation was the lack of patients with $\mathrm{RD}$ not using HCQ as another control group. However, this approach could present other prescription biases, as SLE patients without antimalarial treatment are quite uncommon, except in those with previous toxicity (maculopathy, allergy, long-term remission, among others). The strategy of prioritizing and enrolling the household cohabitants was chosen because of the relevant epidemiological impact of COVID-19. A relevant clinical consideration is related to the severity of RD in the patients included in this cohort, since there were few patients taking biological DMARDs and cyclophosphamide. However, more recently, Zhong et al., in a Chinese retrospective study involving 6228 patients with autoimmune diseases that were enrolled in just 10 days and during sharp decline of COVID-19 outbreak in Hubei found lower risk of infection than patients taking other DMARDs (OR 0.09 [95\% CI 0.01-0.94]; $\mathrm{p}=0.044$ ) [77].

As future perspectives, the shortage of $\mathrm{HCQ}$ with potential effects after withdrawal [78-81] will be further explored during the 24-week follow-up, as well as hospitalization and mortality rate [82].

\section{Conclusion}

This study provides evidence of a non-protective role of chronic HCQ use (5 mg of the sulfate $/ \mathrm{kg} /$ day) concerning uncomplicated COVID-19 in RD patients, regardless of comorbidities, immunosuppression therapy, and social distancing.

\section{Abbreviations \\ BMH: Brazilian Ministry of Health; Cl: Confidence intervals; CQ: Chloroquine; HCQ: Hydroxychloroquine; OR: Odds ratio; pSS: Primary Sjögren syndrome; RA: Rheumatic arthritis; RD: Rheumatic diseases; SLE: Systemic lupus erythematosus.}

\footnotetext{
Acknowledgements

To the Brazilian Society of Rheumatology for technical support and rapid nationwide mobilization. To all the 395 interviewers (medical students and physicians) who collaborated in the study and the participants.
}

\section{Authors' contributions}

MMP, GSP, LHMH, GAF, CDLM, AMK, RMX, APMGR, ESP, ETRN, defined as Steering Committee, and MVGL conceived the study, developed the protocol and wrote the manuscript with input from all other authors. In addition, all authors are responsible for collecting data and processing, management them and statistical analysis. All authors read and approved the final manuscript.

\section{Funding}

Support sponsored by the National Council for Scientific and Technological Development CNPQ.

\section{Availability of data and materials}

The datasets used and/or analysed during the current study are available from the corresponding author on reasonable request.

\section{Declarations}

\section{Ethics approval and consent to participate}

This protocol was approved by the Brazilian Committee of Ethics in Human Research - CONEP on March 27 $7^{\text {th }}, 2020$ (CAAE 30246120.3.1001.5505). The informed consent process was conducted by phone, as CONEP waived the requirement for the written informed consent form due to the COVID-19 social distancing constraints. This study was registered at the Brazilian Registry of Clinical Trials (ReBEC; RBR - 9KTWX6). All sections are in accordance with STROBE guidelines.

\section{Consent for publication}

The consent of publication was given together with the consent of participation fol all participants and Investigators.

\section{Competing interests}

The authors declare that they have no competing interests.

\section{Author details}

${ }^{1}$ Rheumatology Unit of Escola Paulista de Medicina (Unifesp/ EPM), São Paulo, SP, Brazil. ${ }^{2}$ Hospital das Clínicas, Universidade Federal de Minas Gerais (UFMG), Belo Horizonte, MG, Brazil. ${ }^{3}$ Hospital Universitário de Brasília da Universidade de Brasília, EBSERH (HUB-UnB), Brasília, DF, Brazil. ${ }^{4}$ Hospital São Paulo da Universidade Federal de São Paulo, Escola Paulista de Medicina (Unifesp/ EPM), São Paulo, SP, Brazil. ${ }^{5}$ Hospital Universitário Clementino Fraga Filho, Universidade Federal Do Rio de Janeiro (UFRJ), Rio de Janeiro, RJ, Brazil. ${ }^{6}$ Hospital Do Servidor Público Estadual, Instituto de Assistência Médica Ao Servidor Público Estadual (IAMSPE), São Paulo, SP, Brazil. ${ }^{7}$ Santa Casa de Misericórdia Do Rio de Janeiro (HGSCMRJ), Rio de Janeiro, RJ, Brazil. ${ }^{8}$ Rheumatology Division, Hospital das Clínicas HCFMUSP, Faculdade de Medicina, Universidade de São Paulo, São Paulo, SP, Brazil. ${ }^{9}$ Hospital Universitário Lauro Wanderley, Universidade Federal da Paraíba (UFPB), João Pessoa, PB, Brazil. ${ }^{10} \mathrm{Hospital}$ das Clínicas da Universidade Federal de Pernambuco (UFPE), Recife, PE, Brazil. ${ }^{11} \mathrm{Hospital}$ de Clínicas de Porto Alegre, Universidade Federal Do Rio Grande Do Sul (UFRGS), Porto Alegre, RS, Brazil. ${ }^{12}$ Hospital Universitário da Universidade Federal de Juiz de Fora (UFJF), Juiz de Fora, MG, Brazil. ${ }^{13}$ Santa Casa de Misericórdia de Belo Horizonte, Belo Horizonte, MG, Brazil. ${ }^{14}$ Hospital Geral de Fortaleza (HGF), Fortaleza, CE, Brazil. ${ }^{15}$ Hospital Universitário Pedro Ernesto, Universidade Do Estado Do Rio de Janeiro (UERJ), Rio de Janeiro, RJ, Brazil. ${ }^{16}$ Irmandade da Santa Casa de Misericórdia de São Paulo (ISCMSP), São Paulo, SP, Brazil. ${ }^{17}$ Universidade Federal Do Paraná (UFPR), Curitiba, PR, Brazil. ${ }^{18}$ Hospital Universitário Getúlio Vargas Universidade Federal Do Amazonas, Manaus, AM, Brazil. ${ }^{19}$ Pontifícia Universidade Católica de Campinas (PUC-CAMP), Campinas, SP, Brazil. ${ }^{20}$ Instituto de Medicina Integral Professor Fernando Figueira (IMIP/ PE), Recife, PE, Brazil. ${ }^{21}$ Instituto de Ensino E Pesquisa No Sírio Libanês, São Paulo, SP, Brazil. ${ }^{22}$ Fundação de Vigilância Em Saúde Do Amazonas, Manaus, AM, Brazil. ${ }^{23}$ Instituto Leônidas and Maria Deane, Fiocruz, Manaus, AM, Brazil.

${ }^{24}$ Fundação de Medicina Tropical Dr. Heitor Vieira Dourado, Manaus, AM, Brazil.

${ }^{25}$ Hospital Universitário Evangélico Mackenzie (HUEM), Curitiba, PR, Brazil.

${ }^{26}$ Hospital Universitário Cassiano Antonio de Moraes, Universidade Federal Do Espírito Santo, Vitória, ES, Brazil.

Received: 2 April 2021 Accepted: 14 September 2021

Published online: 07 October 2021

\section{References}

1. Zhou F, Yu T, Du R, Fan G, Liu Y, Liu Z, et al. Clinical course and risk factors for mortality of adult inpatients with COVID-19 in Wuhan, China: a retrospective cohort study. Lancet. 2020;395(10229):1054-62. 
2. Peeri NC, Shrestha N, Rahman MS, Zaki R, Tan Z, Bibi S, et al. The SARS, MERS and novel coronavirus (COVID-19) epidemics, the newest and biggest global health threats: what lessons have we learned? Int J Epidemiol. 2020;49(3):717-26.

3. Gupta A, Madhavan MV, Sehgal K, Nair N, Mahajan S, Sehrawat TS, et al. Extrapulmonary manifestations of COVID-19. Nat Med. 2020;26(7):1017-32

4. Zheng KI, Feng G, Liu WY, Targher G, Byrne CD, Zheng MH. Extrapulmonary complications of COVID-19: a multisystem disease? J Med Virol. 2020;93:323-35

5. Yang W, Sirajuddin A, Zhang X, Liu G, Teng Z, Zhao S, et al. The role of imaging in 2019 novel coronavirus pneumonia (COVID-19). Eur Radiol. 2020:30:4874-82.

6. Vabret N, Britton GJ, Gruber C, Hegde S, Kim J, Kuksin M, et al. Immunology of COVID-19: current state of the science. Immunity. 2020;52(6):910-41.

7. McGonagle D, Sharif K, O'Regan A, Bridgewood C. The role of cytokines including interleukin-6 in COVID-19 induced pneumonia and macrophage activation syndrome-like disease. Autoimmun Rev. 2020;19(6):102537.

8. McGonagle D, O'Donnell JS, Sharif K, Emery P, Bridgewood C. Immune mechanisms of pulmonary intravascular coagulopathy in COVID-19 pneumonia. Lancet Rheumatol. 2020;2:e437-45.

9. Liang W, Guan W, Chen R, Wang W, Li J, Xu K, et al. Cancer patients in SARS-CoV-2 infection: a nationwide analysis in China. Lancet Oncol. 2020;21(3):335-7.

10. Al-Quteimat OM, Amer AM. The impact of the COVID-19 pandemic on cancer patients. Am J Clin Oncol. 2020;43(6):452-5.

11. Johnson KM, Belfer JJ, Peterson GR, Boelkins MR, Dumkow LE. Managing COVID-19 in renal transplant recipients: a review of recent literature and case supporting corticosteroid-sparing immunosuppression. Pharmacotherapy. 2020;40(6):517-24.

12. Favalli EG, Agape E, Caporali R. Incidence and clinical course of COVID-19 in patients with connective tissue diseases: a descriptive observational analysis. J Rheumatol. 2020;47(8):1296.

13. Mathian A, Mahevas M, Rohmer J, Roumier M, Cohen-Aubart F, Amador-Borrero B, et al. Clinical course of coronavirus disease 2019 (COVID-19) in a series of 17 patients with systemic lupus erythematosus under long-term treatment with hydroxychloroquine. Ann Rheum Dis. 2020:79(6):837-9.

14. Ouedraogo DD, Tiendrebeogo WJS, Kabore F, Ntsiba H. COVID-19, chronic inflammatory rheumatic disease and anti-rheumatic treatments. Clin Rheumatol. 2020;39(7):2069-75.

15. Sanders JM, Monogue ML, Jodlowski TZ, Cutrell JB. Pharmacologic treatments for coronavirus disease 2019 (COVID-19): a review. JAMA. 2020. https://doi.org/10.1001/jama.2020.6019.

16. Dos Reis Neto ET, Kakehasi AM, de Medeiros PM, Ferreira GA, Marques $\mathrm{CDL}$, da Mota LMH, et al. Revisiting hydroxychloroquine and chloroquine for patients with chronic immunity-mediated inflammatory rheumatic diseases. Adv Rheumatol. 2020;60(1):32.

17. Fanouriakis A, Bertsias G, Boumpas DT. Hydroxychloroquine dosing in systemic lupus erythematosus: response to 'Comment on the 2019 update of the EULAR recommendations for the management of systemic lupus erythematosus by Fanouriakis et al' by Costedoat-Chalumeau et al. Ann Rheum Dis. 2020;79(8):e91.

18. Fanouriakis A, Kostopoulou M, Cheema K, Anders HJ, Aringer M, Bajema I, et al. 2019 Update of the Joint European League Against Rheumatism and European Renal Association-European Dialysis and Transplant Association (EULAR/ERA-EDTA) recommendations for the management of lupus nephritis. Ann Rheum Dis. 2020;79(6):713-23.

19. Wang M, Cao R, Zhang L, Yang X, Liu J, Xu M, et al. Remdesivir and chloroquine effectively inhibit the recently emerged novel coronavirus (2019-nCoV) in vitro. Cell Res. 2020;30(3):269-71.

20. Gautret P, Lagier JC, Parola P, Hoang VT, Meddeb L, Mailhe M, et al. Hydroxychloroquine and azithromycin as a treatment of COVID-19: results of an open-label non-randomized clinical trial. Int J Antimicrob Agents. 2020;56(1):105949.

21. Lagier JC, Million M, Gautret P, Colson P, Cortaredona S, Giraud-Gatineau A, et al. Outcomes of 3,737 COVID-19 patients treated with hydroxychloroquine/azithromycin and other regimens in Marseille, France: a retrospective analysis. Travel Med Infect Dis. 2020;36:101791.
22. Borba MGS, Val FFA, Sampaio VS, Alexandre MAA, Melo GC, Brito M, et al. Effect of high vs low doses of chloroquine diphosphate as adjunctive therapy for patients hospitalized with severe acute respiratory syndrome Coronavirus 2 (SARS-CoV-2) infection: a randomized clinical trial. JAMA Netw Open. 2020;3(4):e208857.

23. Monteiro WM, Brito-Sousa JD, Baia-da-Silva D, Melo GC, Siqueira AM, Val F, et al. Driving forces for COVID-19 clinical trials using chloroquine: the need to choose the right research questions and outcomes. Rev Soc Bras Med Trop. 2020;53:e20200155.

24. Cortegiani A, Ippolito M, Ingoglia G, lozzo P, Giarratano A, Einav S. Update I. A systematic review on the efficacy and safety of chloroquine/hydroxychloroquine for COVID-19. J Crit Care. 2020;59:176-90.

25. Cortegiani A, Ippolito M, Ingoglia G, Einav S. Chloroquine for COVID-19: rationale, facts, hopes. Crit Care. 2020;24(1):210.

26. Cortegiani A, Ingoglia G, Ippolito M, Giarratano A, Einav S. A systematic review on the efficacy and safety of chloroquine for the treatment of COVID-19. J Crit Care. 2020;57:279-83.

27. Cavalcanti AB, Zampieri FG, Rosa RG, Azevedo LCP, Veiga VC, Avezum $A$, et al. Hydroxychloroquine with or without azithromycin in mild-tomoderate Covid-19. N Engl J Med. 2020;383:2041-52.

28. Gentry CA, Humphrey MB, Thind SK, Hendrickson SC, Kurdgelashvili G, Williams RJ 2nd. Long-term hydroxychloroquine use in patients with rheumatic conditions and development of SARS-CoV-2 infection: a retrospective cohort study. Lancet Rheumatol. 2020;2(11):e689-97.

29. Aringer M, Costenbader K, Dorner T, Johnson SR. SLE classification criteria items are not dependent on current activity but may accumulate over time. Response to: 'Do 2019 European League against rheumatism/ American College of Rheumatology classification criteria for systemic lupus erythematosus also indicate the disease activity?' by Teng et al. Ann Rheum Dis. 2020.https://doi.org/10.1136/annrheumdis-2020-217105.

30. Aletaha D, Neogi T, Silman AJ, Funovits J, Felson DT, Bingham CO 3rd, et al. 2010 rheumatoid arthritis classification criteria: an American College of Rheumatology/European League Against Rheumatism collaborative initiative. Ann Rheum Dis. 2010;69(9):1580-8.

31. Shiboski CH, Shiboski SC, Seror R, Criswell LA, Labetoulle M, Lietman TM, et al. 2016 American College of Rheumatology/European League Against Rheumatism classification criteria for primary Sjogren's syndrome: a consensus and data-driven methodology involving three international patient cohorts. Ann Rheum Dis. 2017;76(1):9-16.

32. van den Hoogen F, Khanna D, Fransen J, Johnson SR, Baron M, Tyndall A, et al. 2013 classification criteria for systemic sclerosis: an American College of Rheumatology/European League against Rheumatism collaborative initiative. Arthritis Rheum. 2013;65(11):2737-47.

33. Lundberg IE, Tjarnlund A, Bottai M, Werth VP, Pilkington C, de Visser $M$, et al. 2017 European League Against Rheumatism/American College of Rheumatology classification criteria for adult and juvenile idiopathic inflammatory myopathies and their major subgroups. Arthritis Rheumatol. 2017;69(12):2271-82.

34. Sharp GC, Irvin WS, Tan EM, Gould RG, Holman HR. Mixed connective tissue disease-an apparently distinct rheumatic disease syndrome associated with a specific antibody to an extractable nuclear antigen (ENA). Am J Med. 1972;52(2):148-59.

35. Altman R, Alarcon G, Appelrouth D, Bloch D, Borenstein D, Brandt K, et al. The American College of Rheumatology criteria for the classification and reporting of osteoarthritis of the hand. Arthritis Rheum. 1990;33(11):1601-10.

36. Altman RD, Block DA, Brandt KD, Cooke DV, Greenwald RA, Hochberg MC, et al. Osteoarthritis: definitions and criteria. Ann Rheum Dis, 1990;49(3):201.

37. Javelle E, Gautret P, Simon F. Chikungunya, the emerging migratory rheumatism. Lancet Infect Dis. 2015;15(5):509-10.

38. MdSB. Boletim Epidemiológico-Doença pelo Coronavírus 2019. Ampliação da Vigilância, Medidas não Farmacológicas e Descentralização do Diagnóstico Laboratorial. In: Saúde Md, editor Brasil 2020. 2020.

39. Zen M, Fuzzi E, Astorri D, Saccon F, Padoan R, lenna L, et al. SARSCoV-2 infection in patients with autoimmune rheumatic diseases in northeast Italy: a cross-sectional study on 916 patients. J Autoimmun. 2020;112:102502.

40. Figueroa-Parra G, Aguirre-Garcia GM, Gamboa-Alonso CM, CamachoOrtiz A, Galarza-Delgado DA. Are my patients with rheumatic diseases at higher risk of COVID-19? Ann Rheum Dis. 2020;79(6):839-40. 
41. Gianfrancesco M, Hyrich KL, Al-Adely S, Carmona L, Danila MI, Gossec $L$, et al. Characteristics associated with hospitalisation for COVID-19 in people with rheumatic disease: data from the COVID-19 Global Rheumatology Alliance physician-reported registry. Ann Rheum Dis. 2020;79(7):859-66.

42. D'Silva KM, Serling-Boyd N, Wallwork R, Hsu T, Fu X, Gravallese EM, et al. Clinical characteristics and outcomes of patients with coronavirus disease 2019 (COVID-19) and rheumatic disease: a comparative cohort study from a US "hot spot." Ann Rheum Dis. 2020;80:e64.

43. Marques C, Pinheiro MM, Reis Neto ET, Dantas AT, Ribeiro FM, Melo AKG. COVID-19 in patients with rheumatic diseases: what is the real mortality risk? Ann Rheum Dis. 2020. https://doi.org/10.1136/annrh eumdis-2020-218431.

44. Schrezenmeier E, Dorner T. Mechanisms of action of hydroxychloroquine and chloroquine: implications for rheumatology. Nat Rev Rheumatol. 2020;16(3):155-66.

45. The L. COVID-19: learning from experience. Lancet. 2020;395(10229):1011.

46. Fineberg HV. Ten weeks to crush the curve. N Engl J Med. 2020;382(17):e37.

47. Wei WE, Li Z, Chiew CJ, Yong SE, Toh MP, Lee VJ. Presymptomatic transmission of SARS-CoV-2 - Singapore, January 23-March 16, 2020. MMWR Morb Mortal Wkly Rep. 2020;69(14):411-5.

48. Klompas M, Morris CA, Shenoy ES. Universal masking in the Covid-19 era. N Engl J Med. 2020;383(2):e9.

49. Klompas M, Morris CA, Sinclair J, Pearson M, Shenoy ES. Universal masking in hospitals in the Covid-19 Era. N Engl J Med. 2020;382(21):e63.

50. Wilder-Smith A, Freedman DO. Isolation, quarantine, social distancing and community containment: pivotal role for old-style public health measures in the novel coronavirus (2019-nCoV) outbreak. J Travel Med. 2020;27(2):taaa020. https://doi.org/10.1093/jtm/taaa020.

51. Paton NI, Lee L, Xu Y, Ooi EE, Cheung YB, Archuleta S, et al. Chloroquine for influenza prevention: a randomised, double-blind, placebo controlled trial. Lancet Infect Dis. 2011;11(9):677-83.

52. Paton NI, Goodall RL, Dunn DT, Franzen S, Collaco-Moraes Y, Gazzard BG, et al. Effects of hydroxychloroquine on immune activation and disease progression among HIV-infected patients not receiving antiretroviral therapy: a randomized controlled trial. JAMA. 2012;308(4):353-61.

53. Konig MF, Kim AH, Scheetz MH, Graef ER, Liew JW, Simard J, et al. Baseline use of hydroxychloroquine in systemic lupus erythematosus does not preclude SARS-CoV-2 infection and severe COVID-19. Ann Rheum Dis. 2020;79:1386-8.

54. Carmichael SJ, Charles B, Tett SE. Population pharmacokinetics of hydroxychloroquine in patients with rheumatoid arthritis. Ther Drug Monit. 2003;25(6):671-81.

55. Morita S, Takahashi T, Yoshida Y, Yokota N. Population pharmacokinetics of hydroxychloroquine in Japanese patients with cutaneous or systemic lupus erythematosus. Ther Drug Monit. 2016;38(2):259-67.

56. Cui C, Tu S, En VSJ, Li X, Yao X, Li H, et al. Review on the clinical pharmacology of hydroxychloroquine sulfate for the treatment of COVID-19. Curr Drug Metab. 2020;21:427-35.

57. Yao X, Ye F, Zhang M, Cui C, Huang B, Niu P, et al. In vitro antiviral activity and projection of optimized dosing design of hydroxychloroquine for the treatment of severe acute respiratory syndrome Coronavirus 2 (SARSCoV-2). Clin Infect Dis. 2020;71(15):732-9.

58. Calisher C, Carroll D, Colwell R, Corley RB, Daszak P, Drosten C, et al. Statement in support of the scientists, public health professionals, and medical professionals of China combatting COVID-19. Lancet. 2020;395(10226):e42-3.

59. Gao J, Hu S. Update on use of chloroquine/hydroxychloroquine to treat coronavirus disease 2019 (COVID-19). Biosci Trends. 2020;14(2):156-8.

60. Gao J, Tian Z, Yang X. Breakthrough: chloroquine phosphate has shown apparent efficacy in treatment of COVID-19 associated pneumonia in clinical studies. Biosci Trends. 2020;14(1):72-3.

61. Monti S, Balduzzi S, Delvino P, Bellis E, Quadrelli VS, Montecucco C. Clinical course of COVID-19 in a series of patients with chronic arthritis treated with immunosuppressive targeted therapies. Ann Rheum Dis. 2020;79(5):667-8

62. Lahouati M, Meriglier E, Martin L, Bouchet S, Desclaux A, Bonnet F. COVID-19 infection also occurs in patients taking hydroxychloroquine. J Antimicrob Chemother. 2020;75(7):2014-5.
63. Wang C, Horby PW, Hayden FG, Gao GF. A novel coronavirus outbreak of global health concern. Lancet. 2020;395(10223):470-3.

64. Wu Z, McGoogan JM. Characteristics of and important lessons from the Coronavirus Disease 2019 (COVID-19) Outbreak in China: summary of a report of 72314 cases from the Chinese Center for Disease Control and Prevention. JAMA. 2020;323:1239-42.

65. WHO. Novel Coronavirus (2019-nCoV) situation report-22. 2020.

66. Jung JY, Yoon D, Choi Y, Kim HA, Suh CH. Associated clinical factors for serious infections in patients with systemic lupus erythematosus. Sci Rep. 2019;9(1):9704

67. Ocampo-Piraquive V, Nieto-Aristizabal I, Canas CA, Tobon GJ. Mortality in systemic lupus erythematosus: causes, predictors and interventions. Expert Rev Clin Immunol. 2018;14(12):1043-53.

68. Jorge A, Wallace ZS, Zhang Y, Lu N, Costenbader KH, Choi HK. Allcause and cause-specific mortality trends of end-stage renal disease due to lupus nephritis from 1995 to 2014. Arthritis Rheumatol. 2019;71(3):403-10.

69. Li G, Fan Y, Lai Y, Han T, Li Z, Zhou P, et al. Coronavirus infections and immune responses. J Med Virol. 2020;92(4):424-32.

70. Wan S, Yi Q, Fan S, Lv J, Zhang X, Guo L, et al. Relationships among lymphocyte subsets, cytokines, and the pulmonary inflammation index in coronavirus (COVID-19) infected patients. Br J Haematol. 2020;189(3):428-37.

71. Matucci-Cerinic M, Bruni C, Allanore Y, Clementi M, Dagna L, Damjanov NS, et al. Systemic sclerosis and the COVID-19 pandemic: World Scleroderma Foundation preliminary advice for patient management. Ann Rheum Dis. 2020;79(6):724-6.

72. Orlandi M, Lepri G, Bruni C, Wang Y, Bartoloni A, Zammarchi L, et al. The systemic sclerosis patient in the COVID-19 era: the challenging crossroad between immunosuppression, differential diagnosis and long-term psychological distress. Clin Rheumatol. 2020;39(7):2043-7.

73. Minniti A, Maglione W, Pignataro F, Cappadona C, Caporali R, Del Papa N. Taking care of systemic sclerosis patients during COVID-19 pandemic: rethink the clinical activity. Clin Rheumatol. 2020;39(7):2063-5.

74. Lechien JR, Chiesa-Estomba CM, De Siati DR, Horoi M, Le Bon SD, Rodriguez A, et al. Olfactory and gustatory dysfunctions as a clinical presentation of mild-to-moderate forms of the coronavirus disease (COVID-19): a multicenter European study. Eur Arch Otorhinolaryngol. 2020;277(8):2251-61.

75. Furer , Rondaan C, Heijstek MW, Agmon-Levin N, van Assen S, Bijl M, et al. 2019 update of EULAR recommendations for vaccination in adult patients with autoimmune inflammatory rheumatic diseases. Ann Rheum Dis. 2020;79(1):39-52.

76. Epidemiologists CoSaT. Interm-20-ID-01: standardized surveillance case definitions and national notification for 2019 novel coronavirus disease (COVID-19). 20202020.

77. Zhong J, Shen G, Yang H, Huang A, Chen X, Dong L, et al. COVID-19 in patients with rheumatic disease in Hubei province, China: a multicentre retrospective observational study. Lancet Rheumatol. 2020;2(9):e557-64.

78. Aouhab Z, Hong H, Felicelli C, Tarplin S, Ostrowski RA. Outcomes of systemic lupus erythematosus in patients who discontinue hydroxychloroquine. ACR Open Rheumatol. 2019;1(9):593-9.

79. Peschken CA. Possible consequences of a shortage of hydroxychloroquine for patients with systemic lupus erythematosus amid the COVID-19 Pandemic. J Rheumatol. 2020;47(6):787-90.

80. Jakhar D, Kaur I. Potential of chloroquine and hydroxychloroquine to treat COVID-19 causes fears of shortages among people with systemic lupus erythematosus. Nat Med. 2020;26(5):632.

81. Michaud K, Wipfler K, Shaw Y, Simon TA, Cornish A, England BR, et al. Experiences of patients with rheumatic diseases in the United States during early days of the COVID-19 pandemic. ACR Open Rheumatol. 2020;2(6):335-43.

82. Gomides A. Impact of chronic use of antimalarials on SARS-CoV-2 infection in patients with immune-mediated rheumatic diseases: protocol design for a multicentric observational cohort in Brazil. JMIR Res Protoc. 2020;9:e23532.

\section{Publisher's Note}

Springer Nature remains neutral with regard to jurisdictional claims in published maps and institutional affiliations. 